SUPPORTING INFORMATION

\title{
MEASUREMENT OF HUMIC AND FULVIC ACID CONCENTRATIONS AND DISSOLUTION PROPERTIES BY A RAPID BATCH PROCEDURE
}

André van Zomeren and Rob N.J. Comans

Energy Research Centre of The Netherlands (ECN), Post Office Box 1, 1755 ZG Petten, The Netherlands.

Environmental Science and Technology

Contents (page 1-13):

Page 2-3: Table S1. General correction factors for the calculations of HA, FA, Hy and HON in liquid and solid samples.

Page 4: Table S2. Equations for the calculation of dissolved HA, FA, Hy and HON concentrations.

Page 5-7: Table S3. Equations for the calculation of total HA, FA, Hy and HON concentrations in solid samples.

Page 8-9: Preliminary investigations of DAX-8 and XAD-8 performance (including Figures S1 and S2).

Page 10: Concentration dependent precipitation behaviour of HA.

Page 10: Chemical characterization of HA precipitates obtained at different concentrations.

Page 13: References. 
Please note that template spreadsheets for the calculations of HA, FA, Hy and HON can be obtained from the authors.

Table S1. General correction factors for the calculations of HA, FA, Hy and HON in liquid and solid samples

\begin{tabular}{|l|l|}
\hline Equation & Description \\
\hline$f_{1}=\frac{\left(V_{1}+V_{2}\right)}{V_{1}}$ & Correction factor for acid addition used in HA precipitation \\
\hline$f_{2, i}=\frac{W_{D A X, i} * \text { Moist }_{D A X} * 0.01}{V_{4, i}}+1$ & Used for liquid samples $\left(\mathrm{i}={ }_{\mathrm{L}}\right)$, solid materials $\left(\mathrm{i}=_{\mathrm{FAHHON} 1}\right.$ and \\
\hline$B l_{D A X}=\left(D O C_{B L 2} * f_{2, B L}-D O C_{B L 1}\right)$ & $\left.\mathrm{i}=_{\mathrm{FAHyHON} 2}\right)$ and the blank experiments $\left(\mathrm{i}=_{\mathrm{BL}}\right)$ \\
\hline
\end{tabular}


$V_{1} \quad=$ sample volume used for determination of HA, FA, Hy and HON in liquid samples (mL); Volume after alkaline extraction, centrifugation and decantation for determination of HA, FA, Hy and HON in solid samples.

$V_{2} \quad=$ added volume of $\mathrm{HCl}$ for precipitation of $\mathrm{HA}(\mathrm{mL})$.

$W_{D A X, i} \quad=$ wet weight of DAX-8 applied for adsorption of FA or used in the blank experiment (g)*

Moist $_{D A X}=$ moisture content of the cleaned DAX-8 $(\%)$.

$V_{4, i} \quad=$ sample volume taken into account for the DAX-8 adsorption experiment (mL) after removal of $\mathrm{HA}$ or the amount of $0.1 \mathrm{M} \mathrm{HCl}$ used in the blank experiment* ${ }^{*} i=_{\mathrm{L}}$ for liquid samples, $i==_{\mathrm{FAHyHON} 1}$ and $i=_{\mathrm{FAHyHON} 2}$ for solid materials and $i==_{\mathrm{BL}}$ in the blank experiments.

$D O C_{B L 1}=$ DOC concentration in the $0.1 \mathrm{M} \mathrm{HCl}$ solution used in the blank experiment $(\mathrm{mg} \mathrm{C} / \mathrm{L})$, When $\mathrm{DOC}_{\mathrm{BL} 1}<\mathrm{DTL}, \mathrm{DOC}_{\mathrm{BL} 1}=0$.

$D O C_{B L 2}=\mathrm{DOC}$ concentration in the $0.1 \mathrm{M} \mathrm{HCl}$ in the blank experiment after one hour of equilibration with DAX-8 (mg C/L).

* For simplicity, it is recommended that both $\mathrm{W}_{\mathrm{DAX}, \mathrm{i}}$ and $\mathrm{V}_{4, \mathrm{i}}$ are kept constant $(10 \mathrm{~g}$ and $50 \mathrm{~mL}$, respectively) in both the samples ( $i=\mathrm{L}, \mathrm{FAHyHON1}$ and FAHyHON2) and the blank experiments $(i=\mathrm{BL})$. In that case, the factor $f_{2, i}$ will be constant in all of the calculations. 
Table S2. Equations for the calculation of dissolved HA, FA, Hy and HON concentrations

\begin{tabular}{|c|c|}
\hline Equation & Description \\
\hline$H A=\frac{D O C_{H A} * V_{5}}{V_{1}}-\frac{\left(\left(V_{1}-V_{3}\right) * D O C_{F A H y H O N} * f_{1}\right)}{1000}$ & $\begin{array}{l}\text { Concentration of HA in solution (mg C/L) corrected } \\
\text { for DOC concentration of remaining water in HA } \\
\text { pellet after centrifugation (containing small } \\
\text { concentration of FA+ Hy). Only apply correction if } \\
V_{1}-V_{3}>0 \text {. }\end{array}$ \\
\hline$H y=D O C_{H y} * f_{2, L}-B l_{D A X}$ & Concentration of Hy in solution $(\mathrm{mg} \mathrm{C} / \mathrm{L})$ \\
\hline$[F A+H O N]=\left(D O C_{\text {FАНунОN }} * f_{1}\right)-H y$ & Concentration of $\mathrm{FA}+\mathrm{HON}$ in solution $(\mathrm{mg} \mathrm{C} / \mathrm{L})$ \\
\hline$D O C_{F A, i}=D O C_{F A, \text { measured }, i}-D O C_{B I D A X}$ & $\begin{array}{l}\text { Concentration of } \mathrm{DOC}_{\mathrm{FA}} \text { after correction of blank } \\
\text { DAX-8 contribution }(\mathrm{mg} \mathrm{C} / \mathrm{L}) \text {. Only apply if } \\
\text { DOC }_{\mathrm{FA} \text {,measured, }}-\mathrm{DOC}_{\mathrm{BIDAX}}>0 \text {, else } 0 \text { is used. }\end{array}$ \\
\hline$F A=\frac{\sum_{i=1}^{4} D O C_{F A, i} * V_{11, i}}{V_{4, L}}$ & Concentration of FA in solution (mg C/L) \\
\hline$H O N=[F A+H O N]-F A$ & Concentration of HON in solution (mg C/L) \\
\hline
\end{tabular}

$D O C_{H A}=$ measured $\mathrm{DOC}$ concentration of $\mathrm{HA}(\mathrm{mg} \mathrm{C} / \mathrm{L})$.

$V_{5} \quad=$ added volume of $\mathrm{KOH}$ to dissolve the $\mathrm{HA}$ fraction $(\mathrm{mL})$.

$V_{3} \quad=$ volume of supernatant after acid precipitation and centrifugation $(\mathrm{mL})$.

$V_{11, i} \quad=$ added volume(s) of $\mathrm{KOH}$ to dissolve FA from DAX-8 in liquid samples. Volumes are registered separately $(i=1-4)$.

$D O C_{F A H y H O N}=$ measured DOC concentration of the sample after removal of HA $(\mathrm{mg} \mathrm{C} / \mathrm{L})$. 
$D O C_{H y}=$ measured DOC concentration of the sample after equilibration with DAX-8 $(\mathrm{mg} \mathrm{C} / \mathrm{L})$.

$\mathrm{DOC}_{\mathrm{FA}, \text { measured,i }}=$ DOC concentration(s) in $0.1 \mathrm{M} \mathrm{KOH}$ after dissolution of FA from DAX-8 in liquid samples (mg C/L). DOC concentrations are registered separately $(i=1-4)$.

Table S3. Equations for the calculation of total HA, FA, Hy and HON concentrations in solid samples.

\begin{tabular}{|c|c|}
\hline Equation & Description \\
\hline$M_{\text {Dry }}=M_{\text {Wet }} *\left(100-\right.$ Moist $\left._{\text {Samp. }}\right) / 100$ & Dry sample weight (g) \\
\hline$V_{M}=\left(\frac{\text { Moist }_{\text {Samp. }}}{100} * M_{\text {Wet }}\right)$ & Sample moisture $(\mathrm{mL})$ \\
\hline$V_{A}=V_{1}+V_{2}-V_{8}$ & $\begin{array}{l}\text { Volume correction for acid addition } \\
\left(\mathrm{V}_{2}\right) \text { and the water volume retained in } \\
\text { the pellet containing the HA }\left(\mathrm{V}_{1}-\mathrm{V}_{8}\right) \\
(\mathrm{mL}) \text {. Only apply correction if } \mathrm{V}_{\mathrm{A}}>0 \text {. }\end{array}$ \\
\hline$H y_{1}=\frac{\left(f_{2, F A H y 1} * D O C_{H y 1}-B l_{D A X}\right) * V_{7}}{M_{D r y}}$ & Calculation of $\mathrm{Hy}_{1}(\mathrm{mg} / \mathrm{kg}$ d.m.) \\
\hline$[F A+H O N]_{1}=\frac{D O C_{F A H y H O N 1} * V_{7}}{M_{D r y}}-H y_{1}$ & Calculation of $\mathrm{FA}+\mathrm{HON}_{1}(\mathrm{mg} / \mathrm{kg}$ d.m.) \\
\hline$F A_{1}=\frac{\sum_{i=1}^{4} D O C_{F A 1, i} * V_{9, i}}{M_{d r y}}$ & Calculation of $\mathrm{FA}_{1}$ (mg/kg d.m.) \\
\hline$H y_{2}=\frac{\left(D O C_{H y 2} * f_{2, F A H y 2}-B l_{D A X}\right) *\left(V_{M}+V_{6}\right)}{M_{D r y}}$ & Calculation of $\mathrm{Hy}_{2}$ (mg/kg d.m.) \\
\hline$[F A+H O N]_{2}=\frac{D O C_{F A H y H O N 2} *\left(V_{M}+V_{6}\right) * f_{1}}{M_{D r y}}-H y_{2}$ & Calculation of $\mathrm{FA}+\mathrm{HON}_{2}(\mathrm{mg} / \mathrm{kg}$ d.m.) \\
\hline
\end{tabular}




\begin{tabular}{|l|l|}
\hline$F A_{2}=\frac{\sum_{i=1}^{4} D O C_{F A 2, i} * V_{10, i}}{M_{d r y}}$ & Calculation of $\mathrm{FA}_{2}(\mathrm{mg} / \mathrm{kg} \mathrm{d} . \mathrm{m})$. \\
\hline$H y=H y_{1}+H y_{2}$ & Hy content $(\mathrm{mg} / \mathrm{kg}$ d.m. $)$ \\
\hline$F A=F A_{1}+F A_{2}$ & FA content $(\mathrm{mg} / \mathrm{kg}$ d.m. $)$ \\
\hline$H O N=[F A+H O N]_{1}+[F A+H O N]_{2}-F A$ & Calculation of HON (mg/kg d.m.) \\
\hline$H A=\frac{\left(D O C_{H A} *\left(V_{A}+V_{5}\right)-D O C_{F A H Y H O N 2} * f_{1} * V_{A}\right) *\left(V_{M}+V_{6}\right)}{M_{D r y} * V_{1}}$ & HA content $(\mathrm{mg} / \mathrm{kg}$ d.m. $)$ \\
\hline & \\
\hline
\end{tabular}

$M_{\text {wet }} \quad$ = wet sample weight $(\mathrm{g})$.

Moist $_{\text {samp. }}=$ moisture content of the sample (\%).

$V_{6} \quad=$ added volume of 1 and $0.1 \mathrm{M} \mathrm{HCl}$ to acidify the sample to a $\mathrm{pH}$ of $1(\mathrm{~mL})$.

$V_{7} \quad=$ recovered supernatant after the $0.1 \mathrm{M} \mathrm{HCl} \mathrm{extraction}(\mathrm{mL})$.

$V_{8} \quad=$ recovered supernatant after the HA removal $(\mathrm{mL})$.

$V_{l} \quad=$ recovered supernatant after the $0.1 \mathrm{M} \mathrm{NaOH}$ extraction $(\mathrm{mL})$.

$V_{2} \quad=$ added volume $6 \mathrm{M} \mathrm{HCl}(\mathrm{mL})$.

$V_{5} \quad=$ added volume of $\mathrm{KOH}$ to dissolve the HA fraction $(\mathrm{mL})$.

$V_{9} \quad=$ added volume(s) of $\mathrm{KOH}$ to dissolve FA from DAX-8, $0.1 \mathrm{M} \mathrm{HCl}$ extract. Volumes are registered separately $(i=1-4)$.

$V_{10} \quad=$ added volume(s) of $\mathrm{KOH}$ to dissolve FA from DAX-8, $0.1 \mathrm{M} \mathrm{NaOH}$ extract. Volumes are registered separately $(i=1-4)$. 
$D O C_{H A}=$ measured DOC concentration of HA $(\mathrm{mg} \mathrm{C} / \mathrm{L})$.

$D O C_{F A H Y H O N I}=$ DOC concentration in the recovered supernatant after the $0.1 \mathrm{M} \mathrm{HCl}$ extraction (mg C/L).

$D O C_{\text {FAHYHON2 }}=$ DOC concentration in the recovered supernatant after the HA removal $(\mathrm{mg}$ $\mathrm{C} / \mathrm{L})$.

$D O C_{H y l}=$ measured DOC concentration in the $0.1 \mathrm{M} \mathrm{HCl}$ extract after equilibration with DAX-8 $(\mathrm{mg} \mathrm{C} / \mathrm{L})$.

$D O C_{H y 2}=$ measured DOC concentration in the extract after HA removal and the equilibration with DAX-8 (mg C/L).

$D O C_{F A l}=$ DOC concentration(s) in $0.1 \mathrm{M} \mathrm{KOH}$ after dissolution of FA from DAX-8 in the $0.1 \mathrm{M}$ $\mathrm{HCl}$ extract (mg C/L). DOC concentrations are registered separately $(i=1-4)$.

$D O C_{F A 2}=$ DOC concentration(s) in $0.1 \mathrm{M} \mathrm{KOH}$ after dissolution of FA from DAX-8 in the $0.1 \mathrm{M}$ $\mathrm{NaOH}$ extract (mg C/L). DOC concentrations are registered separately $(i=1-4)$. 
Preliminary investigations of DAX-8 and XAD-8 performance. The adsorption of FA on XAD-8 and DAX-8 was studied at different resin additions and the adsorption time was measured. Moreover, the reversibility of the adsorption process was measured because FA are generally identified on the basis of their adsorption and subsequent desorption from XAD-8 (1-4). The results of these preliminary investigations are given in Figure S 1 and Figure S 2. It should be noted that that the DAX-8 resin tends to adsorb slightly greater amounts (up to 5\%) of FA as compared to XAD-8. These results are consistent with Peuravuori et al. (5). They concluded that the XAD-8 and DAX-8 resins isolate mixtures of components with generally similar structural compositions, although the content of aliphatics within the extracted HS is slightly greater for DAX-8. It should be noted that Peuravuori et al. (5) have based their results on mixtures of HA and FA, whereas we only focus on the equivalency for FA sorption and desorption. We conclude that XAD-8 and DAX-8 are equivalent with regard to the estimation of FA concentrations and that the use of this procedure with DAX-8 is compatible with the standard procedures recommended by the IHSS. 


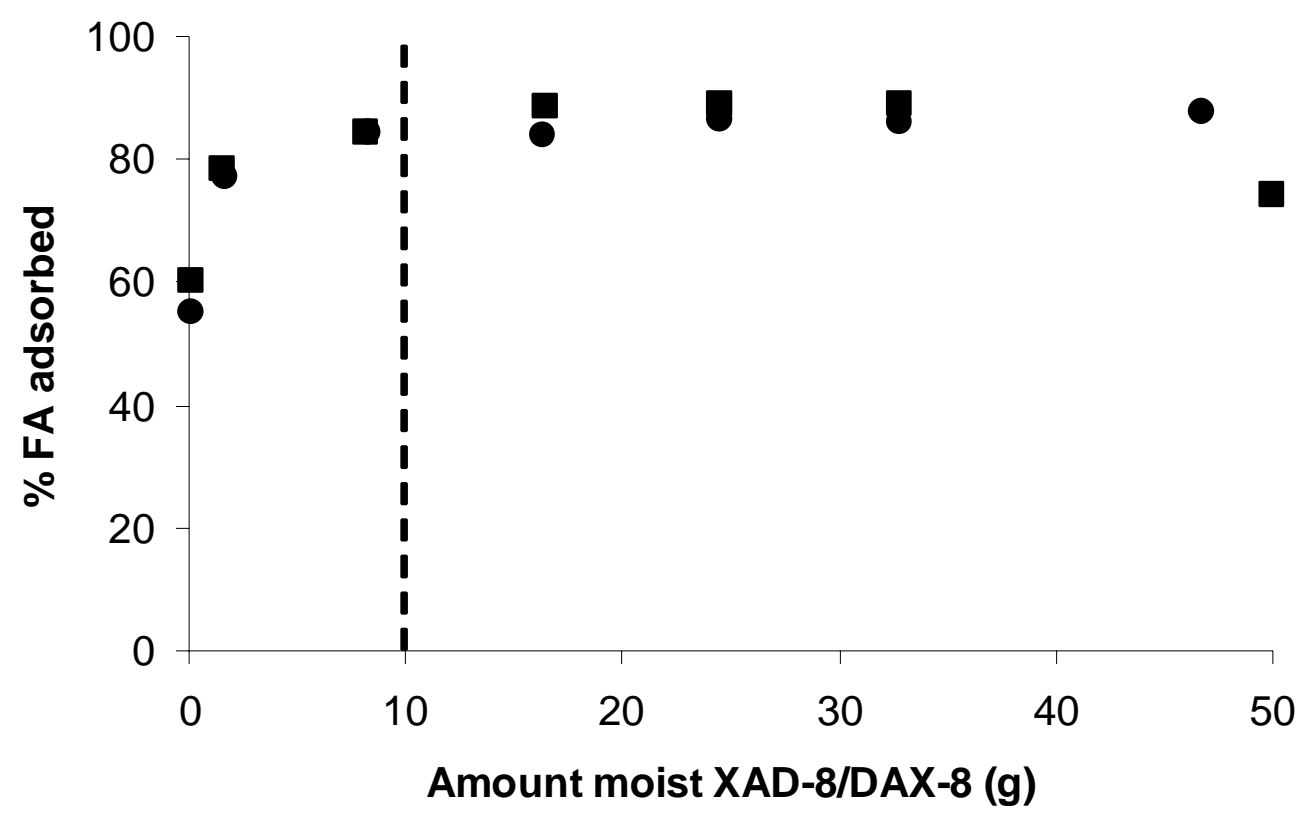

Figure S 1. Adsorption of Elliot soil FA ( $28 \mathrm{mg} \mathrm{C/L}$ ) as a function of the amount of XAD-8 or DAX-8 resin (moist). The circles represent experiments with XAD-8 resin, squares show the results with DAX8 resin. The vertical line indicates the amount of resin selected for the standard procedure.
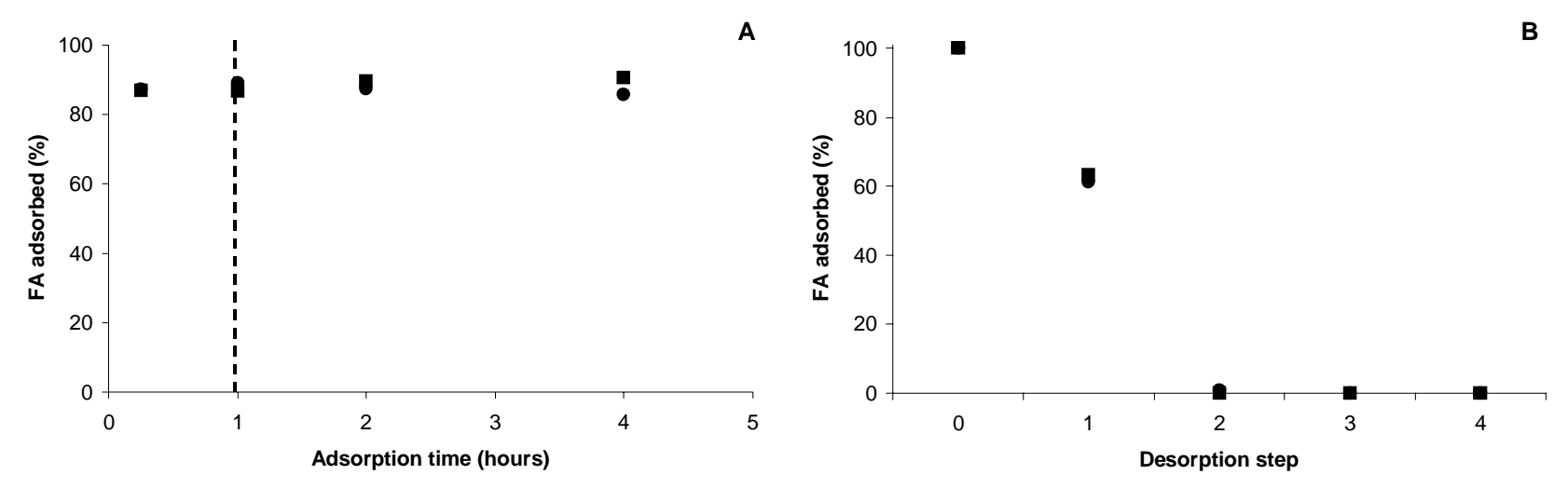

Figure S 2. Adsorption of FA as a function of time (A) and the desorption characteristics of XAD-8 and DAX-8 (B) for Elliot soil FA (28 mg C/L). The experiments were performed with $10 \mathrm{~g}$ of moist resin 
for $50 \mathrm{~mL}$ of sample solution. The vertical line indicates the selected adsorption time for the standard procedure.

\section{Concentration dependent precipitation behaviour of HA.}

Figure $S 3$ reflects the HA recovery from precipitation as a function of the measured HA concentrations. The fitted relationships for solid and aquatic HA can be used to approximately account for the precipitation efficiency. Please note that these general relationships might not be adequate enough in specific samples.
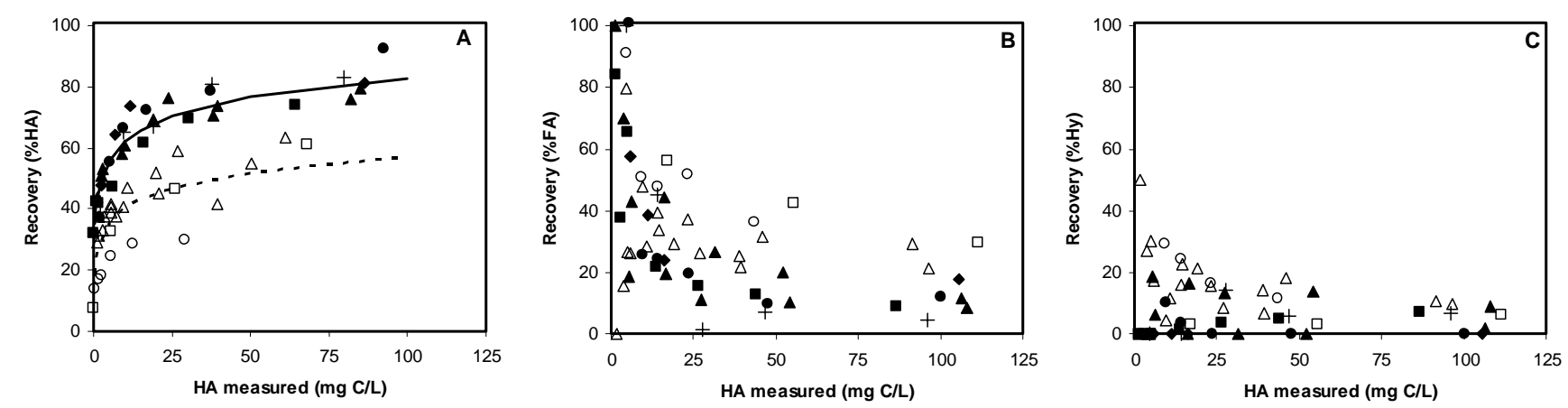

Figure S 3. Recovery of purified HA as a function of the measured HA concentration for the peat ( $\mathbf{\square})$,

Elliot soil ( $\mathbf{\Delta})$, Elliot soil after high-speed centrifugation $(\bullet)$, compost $(\bullet)$ and the landfill waste mixture (+) solid source materials (Part A). The open symbols represent isolated aquatic HA: Suwannee river (O), Landfill leachate $(\square)$ and Zwanenwater $(\triangle)$. The solid line is the fitted curve $\left(y=10.46 \operatorname{Ln}(x)+32.93, r^{2}=0.86, n=38\right)$ based on all data from peat, soil, compost and the landfill waste mixture derived HA, the dashed line is the fitted HA concentration dependency $(y=8.28 \operatorname{Ln}(\mathrm{x})+12.88$, $\mathrm{r}^{2}=0.52, \mathrm{n}=27$ ) based on the data from three aquatic HA samples. Parts B and C show the percentage of DOC (originating from HA) measured as FA and Hy, respectively, as a function of the measured HA concentration. HON was not detected in these samples.

\section{Chemical characterization of HA precipitates obtained at different concentrations}


Additional experiments were performed with HA isolated from compost, to chemically characterize the fractions obtained at different concentrations in the batch method. HA fractions precipitated at five different initial concentrations (10-100 mg C/L) were again purified by dialysis, freeze-dried and chemically characterised by HPSEC, UV/VIS absorbance (254 to $665 \mathrm{~nm})$ and elemental analysis (C, $\mathrm{H}, \mathrm{N}, \mathrm{O})$. The results are shown in Table S4 and S5. The HPSEC chromatograms are shown in Figure S4. The E465/E665 ratio seems to be higher in the original sample, this property is not reflected in the other isolates. It is unclear why the absorbance of the original sample at $665 \mathrm{~nm}$ is relatively low in comparison with all other results, although it should be noted that very little absorption is measured at this wavelength. The other chemical properties seem to be well comparable with each other amongst all samples. The HPSEC chromatograms (Figure S4) show (other than the peak height due to different concentrations) no significant differences in the apparent molecular size distribution. It is therefore concluded that these techniques reveal no significant differences between the HA fractions that were precipitated from low to high concentrations (0.5-100 $\mathrm{mg} \mathrm{C} / \mathrm{L})$.

Table S4: UV/VIS characteristics of previously purified compost HA (original) and re-precipitated compost HA samples that were subsequently dissolved at different concentrations. Aromaticity was calculated from the absorbance at $254 \mathrm{~nm}$ according to (6).

\begin{tabular}{|c|c|c|c|c|c|c|c|c|c|c|c|}
\hline $\begin{array}{l}\text { Precipitation } \\
\text { concentration }\end{array}$ & $\begin{array}{l}\mathrm{DOC} \\
(\mathrm{mg} \\
\mathrm{C} / \mathrm{L}) \\
\end{array}$ & $\begin{array}{c}254 \mathrm{~nm} \\
(\mathrm{abs})\end{array}$ & $\begin{array}{l}280 \mathrm{~nm} \\
(\mathrm{abs})\end{array}$ & $\begin{array}{l}300 \mathrm{~nm} \\
(\mathrm{abs})\end{array}$ & $\begin{array}{l}400 \mathrm{~nm} \\
(\mathrm{abs})\end{array}$ & $\begin{array}{l}465 \mathrm{~nm} \\
\text { (abs) }\end{array}$ & $\begin{array}{l}665 \mathrm{~nm} \\
\text { (abs) }\end{array}$ & $\begin{array}{c}\text { E300/E400 } \\
(-)\end{array}$ & $\begin{array}{c}\begin{array}{c}\text { E465/E665 } \\
\text { ratio }\end{array} \\
(-) \\
\end{array}$ & $\begin{array}{c}\varepsilon(254) \\
\left(\mathrm{mol} / /^{*} \mathrm{~cm}\right)\end{array}$ & $\begin{array}{c}\text { Aromaticity } \\
(\%) \\
\end{array}$ \\
\hline Original & 15.1 & 0.767 & 0.668 & 0.577 & 0.233 & 0.124 & 0.018 & 2.5 & 6.9 & 611 & 33.3 \\
\hline $10 \mathrm{mg} \mathrm{C} / \mathrm{L}$ & 13.5 & 0.731 & 0.626 & 0.541 & 0.235 & 0.142 & 0.058 & 2.3 & 2.5 & 556 & 34.5 \\
\hline $20 \mathrm{mg} \mathrm{C} / \mathrm{L}$ & 15.2 & 0.769 & 0.677 & 0.585 & 0.261 & 0.154 & 0.058 & 2.2 & 2.7 & 534 & 33.4 \\
\hline $30 \mathrm{mg} \mathrm{C} / \mathrm{L}$ & 13.6 & 0.743 & 0.645 & 0.553 & 0.25 & 0.145 & 0.054 & 2.2 & 2.7 & 568 & 35.1 \\
\hline $50 \mathrm{mg} \mathrm{C} / \mathrm{L}$ & 14.4 & 0.767 & 0.675 & 0.584 & 0.25 & 0.145 & 0.055 & 2.3 & 2.6 & 561 & 34.8 \\
\hline $100 \mathrm{mg} \mathrm{C} / \mathrm{L}$ & 14.7 & 0.803 & 0.703 & 0.608 & 0.255 & 0.15 & 0.058 & 2.4 & 2.6 & 572 & 35.4 \\
\hline
\end{tabular}


Table S5: Elemental analysis of previously purified compost HA (original) and re-precipitated compost HA samples that were subsequently dissolved at different concentrations. Elemental composition was determined on dry matter basis. The original material was isolated and purified with the conventional isolation procedure.

\begin{tabular}{|c|c|c|c|c|c|c|}
\hline $\begin{array}{l}\text { Precipitation } \\
\text { concentratio } \\
\mathrm{n}\end{array}$ & $\mathrm{C}$ & $\mathrm{H}$ & $\mathrm{N}$ & $\mathrm{O}$ & $\begin{array}{c}\text { Sum } \\
\text { CHNO }\end{array}$ & $\begin{array}{c}\mathrm{O} / \mathrm{C} \\
\text { Ratio }\end{array}$ \\
\hline Original & 55.78 & 4.82 & 7.77 & 27.71 & 96.1 & 0.61 \\
\hline $10 \mathrm{mg} \mathrm{C} / \mathrm{L}$ & 53.31 & 4.46 & 6.84 & 29.17 & 93.8 & 0.53 \\
\hline $20 \mathrm{mg} \mathrm{C} / \mathrm{L}$ & 54.52 & 4.83 & 7.4 & 29.04 & 95.8 & 0.57 \\
\hline $30 \mathrm{mg} \mathrm{C} / \mathrm{L}$ & 53.35 & 4.74 & 7.26 & 20.55 & 85.9 & 0.56 \\
\hline $50 \mathrm{mg} \mathrm{C} / \mathrm{L}$ & 53.86 & 4.77 & 7.19 & 27.1 & 92.9 & 0.55 \\
\hline $100 \mathrm{mg} \mathrm{C} / \mathrm{L}$ & 54.27 & 4.79 & 7.3 & 27.12 & 93.5 & 0.61 \\
\hline
\end{tabular}

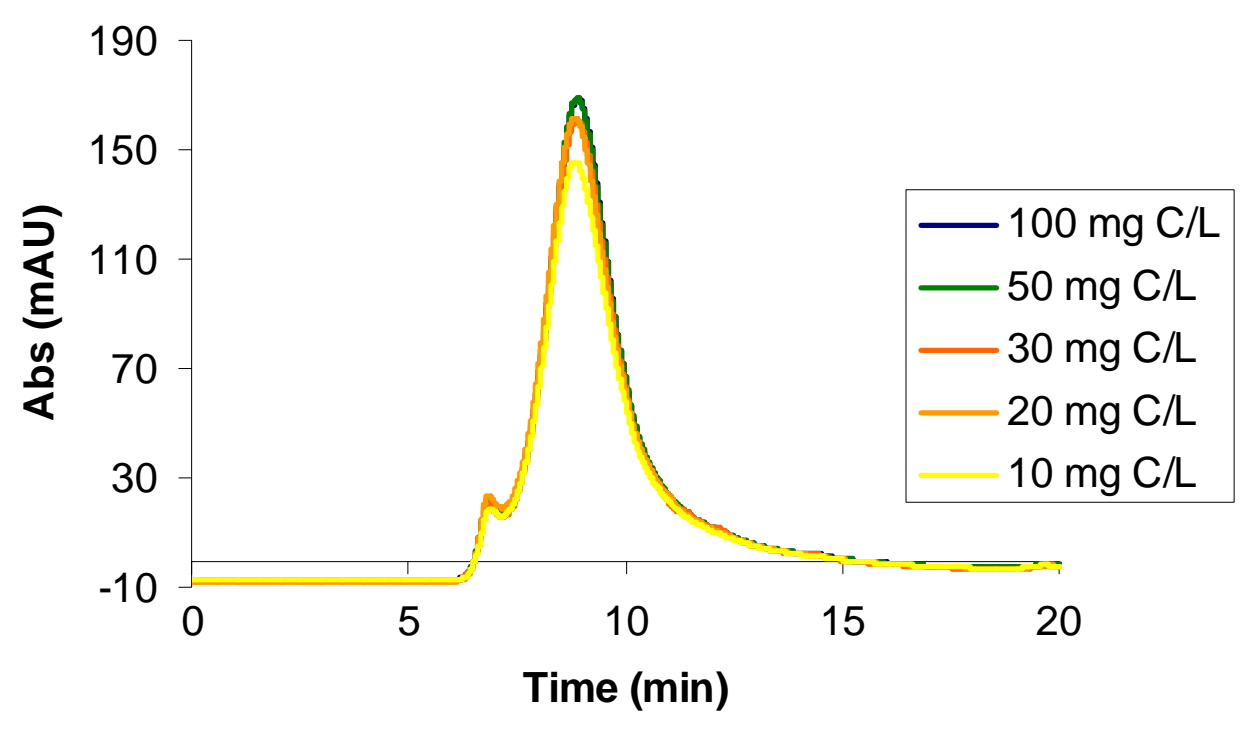

Figure S4: HPSEC chromatograms of previously purified compost HA (original) and re-precipitated compost HA samples that were subsequently dissolved at different concentrations.

Labour intensity and throughput time of the batch and conventional procedures. 
The labour intensity of the batch procedures (for solid and aquatic samples) was compared with that of the conventional procedures. In addition to the labour time, the total throughput time of both procedures was compared (Table S6). It is shown that the total throughput time of the conventional procedures for isolation and purification of soil and aquatic samples is of the order of several weeks. This is largely related to the dialysis and freeze drying steps in the conventional procedures. The batch methods have a total throughput time of about 1-2 days. It should be noted that the conventional procedures are mainly developed to isolate the HS for further characterisation studies. If one would be interested in the concentrations of the specific HS only, DOC can be measured in the samples after the column elution steps of the conventional procedures $(1,2)$. This would eliminate the need for further dialysis and freeze drying. However, the throughput time would still be a factor of 3-6 longer than with the batch method.

The labour time of the procedures is also compared in Table S6. The conventional procedures are very labour intensive and require about 40 hours of work for one sample (depending on the specific laboratory infrastructure and equipment). The batch procedures can be performed within 1.5-4 hours for one sample. It should also be noted that the number of samples that can be handled simultaneously can be easily extended with the batch procedures. For example, about 10 aquatic samples or about 5 solid samples can be processed simultaneously. The labour time per sample is then even further reduced.

Table S6: Comparison of total throughput time and labour time for the conventional isolation and purification procedures and the batch method based on the processing of one sample.

\begin{tabular}{|l|l|l|l|l|l|}
\hline Procedure & $\begin{array}{l}\text { Throughput } \\
\text { time isolation } \\
\text { (days) }\end{array}$ & $\begin{array}{l}\text { Throughput } \\
\text { time } \\
\text { dialysis/freeze } \\
\text { drying (days) }\end{array}$ & $\begin{array}{l}\text { Labour } \\
\text { time } \\
\text { isolation } \\
\text { (hours) }\end{array}$ & $\begin{array}{l}\text { Labour time } \\
\text { dialysis/freeze } \\
\text { drying (hours) }\end{array}$ & $\begin{array}{l}\text { Total labor } \\
\text { time } \\
\text { (hours) }\end{array}$ \\
\hline $\begin{array}{l}\text { Conventional } \\
\text { aquatic }\end{array}$ & 6 & 7 & 40 & 1 & 41 \\
\hline Batch aquatic & 1 & - & $1.5-3$ & - & $1.5-3$ \\
\hline $\begin{array}{l}\text { Conventional } \\
\text { solid }\end{array}$ & 6 & 21 & 40 & 2 & 42 \\
\hline Batch solid & 2 & - & $2-4$ & - & $2-4$ \\
\hline
\end{tabular}




\section{REFERENCES}

(1) Thurman, E. M., Malcolm, R. L. Preparative isolation of aquatic humic substances, Environ. Sci. Technol., 1981, 15, 463-466.

(2) Swift, R. S. Organic matter characterization; In Methods of soil analysis. Part 3. Chemical methods; Sparks, D. L., ed. Soil Sci. Soc. Am.: Madison, WI, 1996; pp 1011-1069.

(3) Hayes, M. H. B.; Swift, R. S. Genesis, isolation, composition and structures of soil humic substances; In Soil colloids and their associations in aggregates; de Boodt, M. F., ed. Plenum Press: New York, 1990; pp 245-305.

(4) Aiken, G. R., Thurman, E. M., Malcolm, R. L. Comparison of XAD macroporous resins for the concentration of fulvic acid from aqueous solution, Anal. Chem., 1979, 51, 1799-1803.

(5) Peuravuori, J., Lehtonen, T., Pihlaja, K. Sorption of aquatic humic matter by DAX-8 and XAD-8 resins - Comparative study using pyrolysis gas chromatography

5, Anal. Chim. Acta, 2002, 471, 219-226.

(6) Chin, Y. P., Aiken, G. R., O'Loughlin, E. Molecular weight, polydispersity, and spectroscopic properties of aquatic humic substances, Environ. Sci. Technol., 1994, 28, 1853-1858. 